\title{
Weight status and dietary intake determine serum leptin concentrations in pregnant and lactating women and their infants
}

\author{
Sanna Vähämiko ${ }^{1,2 *}$, Erika Isolauri ${ }^{1,3,4}$ and Kirsi Laitinen ${ }^{1,5}$ \\ ${ }^{1}$ Functional Foods Forum, University of Turku, 20014 Turku, Finland \\ ${ }^{2}$ Department of Biochemistry and Food Chemistry, University of Turku, 20014 Turku, Finland \\ ${ }^{3}$ Department of Paediatrics, University of Turku, 20014 Turku, Finland \\ ${ }^{4}$ Department of Paediatrics, Turku University Hospital, Turku, Finland \\ ${ }^{5}$ Institute of Biomedicine, University of Turku, 20014 Turku, Finland \\ (Submitted 26 July 2012 - Final revision received 19 December 2012 - Accepted 8 January 2013 - First published online 22 February 2013)
}

\begin{abstract}
Leptin regulates energy homeostasis and immune and metabolic functions. Highly elevated leptin concentrations during pregnancy may be associated with aberrations in maternal metabolism and long-term health consequences both in women and children. The objective of the present study was to evaluate whether dietary counselling, probiotic supplementation, maternal characteristics or dietary intake during pregnancy has an impact on serum leptin concentrations in women, cord blood or in children. A total of 256 pregnant women were randomised to a control group ( $n$ 85) or to receive dietary counselling with probiotics $(n 85)$ or placebo $(n$ 86). Dietary counselling aimed at affecting the type of fat used and to increase the amount of fibre in the women's diet. Women's dietary intake and serum leptin concentrations were analysed at the first and third trimesters of pregnancy and at 1 month postpartum. Furthermore, leptin concentrations were measured from the cord blood and from children's serum at 1 and 6 months of age. Weight status and dietary composition were the key determinants of leptin concentrations. Specifically, high dietary fibre and low SFA intakes were related to low serum leptin concentrations in women. Female sex and birth weight were associated with higher infant leptin, whereas cord blood leptin was additionally affected by maternal leptin concentration and protein intake. Probiotics or dietary counselling did not affect leptin concentrations. Weight control to recommended levels and modification of diet towards higher fibre and lower SFA intakes during pregnancy may through leptin concentrations provide health benefits to both women and children.
\end{abstract}

\section{Key words: Leptin: Pregnancy: Dietary counselling: Fibre}

Adipokine leptin regulates energy homeostasis and immune and metabolic functions ${ }^{(1)}$. Its concentration reflects the amount of body fat, being typically highly elevated in overweight individuals ${ }^{(1)}$ who concomitantly manifest leptin resistance ${ }^{(2,3)}$. Elevated leptin concentrations have also been detected in patients with cardiovascular and metabolic diseases $^{(3-5)}$ as well as in asthmatic and allergic individuals ${ }^{(6-8)}$, suggesting leptin's contribution in the onset or progression of these diseases. During pregnancy, highly elevated leptin concentrations are associated with aberrations in maternal metabolism $^{(9)}$ and, thereafter, an increased risk of gestational diabetes and pregnancy-induced hypertension ${ }^{(10,11)}$. When taking into account the fact that an adverse maternal metabolic status, including overweight and elevated leptin concentration, has been suggested to programme offspring's later risk for obesity and metabolic and cardiovascular disorders $^{(12,13)}$, it may be assumed that controlling the pregnancy-related increase in leptin concentrations may provide clinically significant health benefits for both women and their infants.

Factors determining leptin concentrations during pregnancy and in early infancy are poorly known. Nevertheless, dietary composition, in particular the amount and quality of carbohydrates, fibre and fat ${ }^{(14-16)}$, as well as the use of probiotic bacteria $^{(17-19)}$, has been suggested to modify other inflammatory markers and the risk of metabolic and immunological diseases. Therefore, we aimed here to evaluate whether dietary counselling, probiotic supplementation, dietary intake or maternal characteristics during pregnancy would have an impact on serum leptin concentrations in women, cord blood or in children.

\section{Subjects and methods}

Subjects and study design

The study population comprised pregnant women participating in an ongoing, prospective, randomised mother and

Abbreviation: DELFIA, dissociation-enhanced lanthanide fluorescent immunoassay. 
infant nutrition guidance and probiotic study ${ }^{(20,21)}$. Recruitment took place during their first visit to maternal welfare clinics in South-West Finland. Criteria for inclusion were early pregnancy $(<17$ weeks $)$ and allergy in the family (mother, father or sibling of the unborn child) and for exclusion chronic diseases such as diabetes or coeliac disease. A total of 256 subjects were recruited and randomised into three groups: a dietary counselling group with probiotic supplementation ( $n$ 85) or with placebo ( $n$ 86) and control group ( $n$ 85) with placebo. Women in the dietary counselling groups received individualised nutritional advice during the study visits and food products supporting the achievement of the recommended diet. In addition, they received in a doubleblind manner either probiotic capsules containing Lactobacillus rhamnosus GG (American Type Culture Collection 53103; Valio Limited) and Bifidobacterium lactis Bb12 (Chr. Hansen), $10^{9}$ colony-forming units/d each, or placebo capsules that contained microcrystalline cellulose and dextrose anhydrate but no nutrients. Women in the control group received placebo capsules in a single-blind manner. Randomisation was based on a randomisation list, drawn up by a statistician, who was not involved in the study visit. All women received health and dietary counselling in maternal welfare clinics according to a national programme. The present study was conducted according to the guidelines laid down in the Declaration of Helsinki, and we certify that all other applicable institutional and governmental regulations concerning the ethical use of human volunteers were followed throughout this research. The study was approved by the Ethical Committee of the Hospital District of South-West Finland. Written informed consent was obtained from all the women involved. The present study is registered as a clinical study (NCT00167000; section 3, http://www.clinicaltrials.gov).

The participants visited the study clinic at the first (mean 14, range 7-18 weeks), second (mean 24, range 20-27 weeks) and third (mean 34, range 30-37 weeks) trimesters of pregnancy, and, with their infants, at 1 month postpartum (mean 1.3 months, range $0.03-3.6$ months).

\section{Dietary counselling and food records}

Dietary counselling was aimed at affecting the type of fat used and to increase the amount of fibre in the women's diet as described in detail elsewhere ${ }^{(20)}$. The consumption of vegetables, fruits, whole-grain bread, cereals, leaner meat products, low-fat cheese and milk products as well as the use of vegetable oils and margarines was encouraged. Fish was recommended as one of the main meals twice per week. The achievement of an appropriate diet was supported by providing the mother with conventional food products available on the market with favourable fat and fibre content (e.g. rapeseed oil-based spreads, salad dressing and fibreenriched pasta, muesli and cereals) for use at home. Women were given a recommendation on the amount of these products to be used daily, and the products were provided until the mothers discontinued exclusive breast-feeding (maximum 6 months). Women in the control group did not receive dietary counselling during the study visits.
Food and nutrient intakes were evaluated using a $3 \mathrm{~d}$ food record, including one weekend day, at the first, second and third trimesters of pregnancy and at 1 month postpartum. Daily energy and nutrient intakes were calculated using the Micro-Nutrica ${ }^{\circledR}$ software program version 2.5 (Research Centre of the Social Insurance Institution).

\section{Clinical evaluation}

Information on age, parity, smoking and education was obtained by interviews. Weight before pregnancy was taken from the records of the maternal welfare clinic and used in the calculation of pre-pregnancy BMI as weight $(\mathrm{kg})$ divided by the square of height $\left(\mathrm{m}^{2}\right)$. Weight during pregnancy was measured by a research nurse at every study visit and height at the first visit. Women's weight before labour was recorded at the last prenatal visit to a maternal welfare clinic or in hospital within 1 week before delivery, and used for the determination of the total weight gain during pregnancy. Weight gain during pregnancy was classified as normal, excessive or low as previously described elsewhere ${ }^{(22)}$. Infants' weights at birth were obtained from hospital records; at 1 month of age it was measured by the research nurse. The prevalence of atopy in women was defined as atopic sensitisation assessed by skin prick tests at the third trimester of pregnancy, as described elsewhere ${ }^{(23)}$.

\section{Sampling and analytical methods}

Venous blood samples were taken from women after overnight fasting at the first and third trimesters of pregnancy and at 1 month postpartum. Children's blood samples were taken at 1 month of age without fasting. Serum samples were stored in $-70^{\circ} \mathrm{C}$ until the analysis in the NIHR Cambridge Biomedical Research Centre, Core Biochemical Assay Laboratory.

Analyses were performed with an in-house, two-site, microtitre plate-based, time-resolved fluorometric (dissociationenhanced lanthanide fluorescent immunoassay, DELFIA) assay (Perkin-Elmer) using DELFIA multibuffer as an assay buffer and as a diluent for biotinylated antibody and streptavidin. Briefly, the microtitre plate was coated with a monoclonal anti-leptin-capture antibody before the sample was added to the plate along with DELFIA multibuffer. After the incubation and washing of the plate, biotinylated polyclonal anti-human leptin detection antibody was added and the plate was incubated and washed again. Finally, europium-labelled streptavidin was added, the plate was washed and the enhancement solution was added to generate fluorescence. Assays were run in duplicate in $20 \mu \mathrm{l}$ of sample per well and dilution series of human recombinant leptin were used as a calibrator. The lower limit of detection was $0.1 \mathrm{ng} / \mathrm{ml}$ (in-house data), and the between-batch imprecision was $7 \cdot 1 \%$ at $2 \cdot 7 \mathrm{ng} / \mathrm{ml}, 3 \cdot 9 \%$ at $14.9 \mathrm{mg} / \mathrm{ml}$ and $5.7 \%$ at $54.9 \mathrm{ng} / \mathrm{ml}$ (in-house data). Antibodies and standards were purchased from R\&D Systems Europe.

\section{Statistics}

Characteristics of the women and children are presented as means with ranges or as a proportion of the study subjects. 
Dietary intakes of energy and nutrients are shown as the intake during pregnancy (mean of the first, second and third trimesters) and after pregnancy (mean of 1 and 6 months postpartum). ANOVA was used to study the differences between the groups in the intake of energy and energyyielding nutrients.

Serum leptin concentrations measured in women at the first and third trimesters of pregnancy and at 1 month postpartum as well as in the cord blood and infant serum at 1 and 6 months of age were the primary variables in the present study. ANCOVA was used to compare the women's serum leptin concentrations between the groups. Baseline (measured at the first trimester of pregnancy) leptin concentration was included as a covariate. Results are given as geometric means with 95\% CI. ANOVA was used for the comparison of leptin concentrations in children's serum. Results are given as geometric means with 95\% CI. ANCOVA for repeated measures for women and ANOVA for repeated measures for children were conducted in order to study within-subject changes in serum leptin concentrations. Group effect, time effect and interactions between group and time were all analysed.

As an exploratory analysis, the associations between maternal characteristics and serum leptin concentrations were studied further. First, in order to identify potential explanatory factors for serum leptin concentrations in women, cord blood and in children, Pearson's correlations (including factors such as maternal age, pre-pregnancy weight and BMI, dietary intake of energy and nutrients, smoking before or during pregnancy and duration of lactation in women, and, additionally, sex, birth weight and weight at 1 and 6 months of age in offspring) were used. ANOVA was also used to study the differences in serum leptin concentrations according to women's BMI $\left(<25\right.$ or $\left.\geq 25 \mathrm{~kg} / \mathrm{m}^{2}\right)$, weight gain during pregnancy (less or within the recommendation, or more than recommended), atopy (skin prick test positivity or negativity), smoking before or during pregnancy (yes or no), exclusive breast-feeding at 1 month of age (yes or no) and breast-fed at 6 months of age (yes or no). The associations between dietary intake and leptin concentrations were studied further by dividing women into tertiles according to their intake of energy and nutrients (total fat, SFA, MUFA, PUFA, protein, carbohydrates, sucrose, fructose, glucose, total fibre, soluble fibre and non-soluble fibre) both as quantitatively and as relative to energy intake (percentage of energy). Then, ANOVA was used to study the differences in serum leptin concentrations between the tertiles. Thereafter, multivariate forward stepwise regression models were applied. The interventions (dietary counselling and probiotic supplementation) were forced to all models, and other factors introduced into the women's model were baseline leptin concentration at the beginning of pregnancy, pre-pregnancy BMI, weight gain during pregnancy, intakes of energy, protein, carbohydrates, fibre and SFA as a mean of the third trimester and 1 month postpartum as continuous variables. In the cord blood models, the included factors were dietary counselling, probiotic supplementation, maternal pre-pregnancy BMI, weight gain during pregnancy and maternal intakes of energy, protein, carbohydrates, fibre and fructose as a mean of the first, second and third trimesters of pregnancy as well as birth weight and sex of the infant. When modelling infant serum leptin concentrations, dietary counselling and probiotic supplementation were again forced into the model and other factors included were maternal pre-pregnancy BMI and maternal serum leptin concentration as a mean of the third trimester and 1 month postpartum, maternal dietary intake of energy, protein, carbohydrates and fibre as a mean of the third trimester of pregnancy and 1 month postpartum as well as sex and birth weight of the infant. The criterion for entry was $P<0 \cdot 10$ to achieve a model with significant or nearly significant factors combined with the effect of dietary counselling and probiotic supplementation.

All statistical analyses were performed on SPSS for Windows (version 15.0; SPSS, Inc.).

\section{Results}

\section{Subject characteristics}

Subject characteristics are shown in Table 1. All women were Caucasian, in good health and well educated; $81 \%$ in the control group, $71 \%$ in the dietary counselling with placebo group and $79 \%$ in the dietary counselling with probiotics group had completed a college or university education. The dietary intakes of energy and energy-yielding nutrients are shown in Table 2 .

\section{Serum leptin concentrations in women}

Women's serum leptin concentrations increased significantly from the first to the third trimester of pregnancy $(P<0 \cdot 001)$, decreasing again after delivery $(P<0 \cdot 001)$ (Table 3$)$. Dietary counselling or probiotic supplementation had no influence on women's serum leptin concentrations (Tables 3 and 4).

Statistical analyses suggested that women's baseline leptin concentration as well as women's pre-pregnancy BMI and weight gain during pregnancy explained their serum leptin concentrations during the follow-up (Table 4). Indeed, overweight women (pre-pregnancy BMI $>25 \mathrm{~kg} / \mathrm{m}^{2}$ ) had significantly higher serum leptin concentration $(34.77 \mathrm{ng} / \mathrm{ml})$ when compared with normal-weight women (BMI $<25 \mathrm{~kg} / \mathrm{m}^{2}$, $19 \cdot 12 \mathrm{ng} / \mathrm{ml})(P<0 \cdot 001)$. Furthermore, women who gained weight more than what is recommended during pregnancy had higher leptin concentrations $(29.36 \mathrm{ng} / \mathrm{ml})$ compared with women whose weight gain was within the recommendations or less than recommended $(18.88 \mathrm{ng} / \mathrm{ml})(P<0.001)$. An inverse relationship of serum leptin concentration with dietary fibre intake and positive with the intake of SFA was detected (Table 4). The associations between dietary intake and leptin concentration were studied further by dividing women into tertiles according to their fibre and SFA (mean of the third trimester and 1 month postpartum) intakes. These analyses revealed that women in the lowest tertile of fibre intake as adjusted for energy intake had higher serum leptin (mean of the third trimester and 1 month postpartum) concentration $(25.68 \mathrm{ng} / \mathrm{ml})$ compared with women in the middle $(22.55 \mathrm{ng} /$ $\mathrm{ml})$ or highest $(19.33 \mathrm{ng} / \mathrm{ml})$ tertile of fibre intake $(P=0.033)$. 
Table 1. Characteristics of women and their infants in the study groups

(Mean values, ranges and percentages)

\begin{tabular}{|c|c|c|c|c|c|c|c|c|c|}
\hline & \multicolumn{3}{|c|}{$\begin{array}{l}\text { Dietary counselling with } \\
\text { probiotics }(n 85)\end{array}$} & \multicolumn{3}{|c|}{$\begin{array}{l}\text { Dietary counselling with } \\
\text { placebo }(n 85)\end{array}$} & \multicolumn{3}{|c|}{ Control ( $n 84)$} \\
\hline & Mean & Range & $\%$ & Mean & Range & $\%$ & Mean & Range & $\%$ \\
\hline \multicolumn{10}{|l|}{ Women } \\
\hline Age (years) & $29 \cdot 7$ & $20.7-37.6$ & & $30 \cdot 0$ & $17 \cdot 6-44 \cdot 2$ & & $30 \cdot 2$ & $17 \cdot 6-44 \cdot 2$ & \\
\hline Pre-pregnancy BMI $\left(\mathrm{kg} / \mathrm{m}^{2}\right)$ & $22 \cdot 9$ & $17 \cdot 4-31 \cdot 8$ & & $24 \cdot 3$ & $18 \cdot 2-40 \cdot 7$ & & 23.7 & $17 \cdot 4-40 \cdot 7$ & \\
\hline Postpartum BMI $\left(\mathrm{kg} / \mathrm{m}^{2}\right)$ & $24 \cdot 8$ & $18 \cdot 9-35 \cdot 9$ & & 25.9 & $19 \cdot 5-35 \cdot 8$ & & $25 \cdot 4$ & $18 \cdot 6-35 \cdot 9$ & \\
\hline Pre-pregnancy $\mathrm{BMI} \geq 25 \mathrm{~kg} / \mathrm{m}^{2}$ & & & $18 \cdot 8$ & & & $35 \cdot 3$ & & & 29.8 \\
\hline Weight gain during pregnancy $(\mathrm{kg})$ & $15 \cdot 0$ & $5.5-4.4$ & & $14 \cdot 8$ & $0-26 \cdot 0$ & & $14 \cdot 8$ & $0-26 \cdot 0$ & \\
\hline Weight gain within the recommendations & & & $16 \cdot 9$ & & & $20 \cdot 5$ & & & $21 \cdot 8$ \\
\hline Less than recommended & & & $49 \cdot 4$ & & & 38.5 & & & $32 \cdot 1$ \\
\hline More than recommended & & & 33.8 & & & $41 \cdot 0$ & & & $46 \cdot 2$ \\
\hline Skin prick test positive & & & $61 \cdot 7$ & & & $55 \cdot 1$ & & & $56 \cdot 4$ \\
\hline Smoking before pregnancy & & & $16 \cdot 5$ & & & $21 \cdot 2$ & & & 15.5 \\
\hline Smoking during pregnancy & & & $1 \cdot 2$ & & & $6 \cdot 4$ & & & $6 \cdot 3$ \\
\hline Duration of pregnancy (weeks) & 39.9 & $36 \cdot 9-42 \cdot 3$ & & 39.9 & $30 \cdot 3-42 \cdot 3$ & & 40.1 & $34 \cdot 9-42 \cdot 1$ & \\
\hline \multicolumn{10}{|l|}{ Infants } \\
\hline Male & & & 52.5 & & & $49 \cdot 4$ & & & $56 \cdot 6$ \\
\hline Birth weight (g) & 3485 & $2250-4750$ & & 3641 & $2880-4400$ & & 3600 & $2090-4660$ & \\
\hline Birth height $(\mathrm{cm})$ & $50 \cdot 7$ & $46 \cdot 0-5 \cdot 0$ & & $51 \cdot 4$ & $48 \cdot 0-55 \cdot 0$ & & $51 \cdot 0$ & $44 \cdot 0-57 \cdot 0$ & \\
\hline Weight at 1 month of age $(\mathrm{g})$ & 4753 & $3270-6600$ & & 4754 & $3320-5780$ & & 4739 & $3100-6570$ & \\
\hline Weight at 6 months of age $(\mathrm{g})$ & 8138 & $6100-10600$ & & 8265 & $5180-11560$ & & 8216 & $6120-11000$ & \\
\hline Breast-fed exclusively 1 month of age & & & $82 \cdot 7$ & & & $78 \cdot 4$ & & & $86 \cdot 6$ \\
\hline Breast-fed at 6 months of age & & & $68 \cdot 0$ & & & $76 \cdot 0$ & & & $75 \cdot 0$ \\
\hline
\end{tabular}

Instead, no significant difference in leptin concentrations between the tertiles was detected based on the women's dietary intake of SFA as quantitatively (T1: $20.76 \mathrm{ng} / \mathrm{ml}$, T2: $23.43 \mathrm{ng} / \mathrm{ml}$ and T3: $24.03 \mathrm{ng} / \mathrm{ml}, P=0.349)$ or as adjusted for energy intake (T1: $20 \cdot 41 \mathrm{ng} / \mathrm{ml}, \mathrm{T} 2: 22 \cdot 69 \mathrm{ng} / \mathrm{ml}$ and T3: $24 \cdot 17 \mathrm{ng} / \mathrm{ml}, P=0 \cdot 276$ ).

\section{Cord blood and infant serum leptin concentrations}

Leptin concentration was significantly higher in the cord blood when compared with concentrations in children's serum at 1 month of age $(P<0 \cdot 001)$, whereas no significant change was detected between 1 and 6 months of age $(P=0.407)$ (Table 3). No significant differences were found in children's serum leptin concentrations according to the mother's study group (Table 3).

Based on the statistical analyses, explanatory factors for cord blood leptin concentrations were infant birth weight and sex as well as maternal leptin concentration and protein intake during pregnancy (Table 5). Indeed, the mean cord blood leptin concentration was significantly lower in boys $(8.59 \mathrm{ng} / \mathrm{ml})$ compared with girls $(14.81 \mathrm{ng} / \mathrm{ml})(P<0.001)$. When dividing infants into tertiles according to their birth weight, cord blood leptin concentration was significantly lower in the lowest tertile of birth weight $(\mathrm{T} 1,7 \cdot 32 \mathrm{ng} / \mathrm{ml})$ compared with the middle (T2, $11.79 \mathrm{ng} / \mathrm{ml})$ or highest (T3, $15.35 \mathrm{ng} / \mathrm{ml})$ tertile $(P>0 \cdot 001)$. Similarly, in the lowest tertile of maternal leptin concentration, cord blood leptin concentration was significantly lower (T1, 7.90 ng/ml) compared with the middle $(\mathrm{T} 2,10.86 \mathrm{ng} / \mathrm{ml})$ or highest $(\mathrm{T} 3,13.73 \mathrm{ng} /$ $\mathrm{ml})$ tertile $(P=0.002)$. Instead, when dividing mothers according to their protein intake during pregnancy, cord blood leptin concentration was significantly lower in the highest protein intake tertile (T3, $8.18 \mathrm{ng} / \mathrm{ml}$ ) compared with the middle
$(\mathrm{T} 2,13 \cdot 15 \mathrm{ng} / \mathrm{ml})$ or lowest $(\mathrm{T} 1,12 \cdot 13 \mathrm{ng} / \mathrm{ml})$ tertile of protein intake $(P=0 \cdot 005)$.

Birth weight and sex determined serum leptin concentrations also during infancy (mean of 1 and 6 months of age; Table 6). Boys still had significantly lower serum leptin concentrations at 1 month of age $(3.03 \mathrm{ng} / \mathrm{ml})$ compared with girls $(4.20 \mathrm{ng} / \mathrm{ml})(P=0.007)$, whereas at 6 months of age, no significant difference in leptin concentration between male $(3.21 \mathrm{ng} / \mathrm{ml})$ and female $(3.83 \mathrm{ng} / \mathrm{ml}, P=0.063)$ infants was detected. Maternal characteristics, leptin concentrations, dietary factors or dietary counselling of pregnant women did not significantly explain serum leptin concentrations during infancy, but according to the multivariate regression model, probiotics tended to increase infant leptin concentration ( $P=0.090$; Table 6).

The positive relationship between infant weight and leptin concentration was detected in all the studied time points: at birth, $r 0.457, P<0.001$; at 1 month of age, $r 0.298, P<0.001$; at 6 months of age, $r 0.492, P<0 \cdot 001$. Additionally, a weak negative association between cord blood leptin concentration and infant weight at 6 months of age was found $(r-0 \cdot 163$, $P=0.044)$.

\section{Discussion}

In the present study, we described the increase in women's serum leptin concentrations from the first to the third trimester of pregnancy and then the decrease after delivery. The key determinant of leptin concentration in women seemed to be their weight status including both pre-pregnancy BMI and weight gain during pregnancy. The novel findings here suggest that a high dietary intake of fibre and a low intake of SFA may help to control serum leptin concentrations in women. Infants' leptin concentrations at 1 month of age 
Table 2. Dietary intake of energy and energy-yielding nutrients in women (Mean values and $95 \%$ confidence intervals)

\begin{tabular}{|c|c|c|c|c|c|c|c|c|c|c|c|c|c|c|}
\hline & \multicolumn{4}{|c|}{ Dietary counselling with probiotics } & \multicolumn{4}{|c|}{ Dietary counselling with placebo } & \multicolumn{4}{|c|}{ Controls } & \multirow[b]{3}{*}{$P^{*}$} & \multirow[b]{3}{*}{$P \dagger$} \\
\hline & \multicolumn{2}{|c|}{ During pregnancy* } & \multicolumn{2}{|c|}{ After pregnancy $\dagger$} & \multicolumn{2}{|c|}{ During pregnancy ${ }^{\star}$} & \multicolumn{2}{|c|}{ After pregnancy $\dagger$} & \multicolumn{2}{|c|}{ During pregnancy* } & \multicolumn{2}{|c|}{ After pregnancy† } & & \\
\hline & Mean & $95 \% \mathrm{Cl}$ & Mean & $95 \% \mathrm{Cl}$ & Mean & $95 \% \mathrm{Cl}$ & Mean & $95 \% \mathrm{Cl}$ & Mean & $95 \% \mathrm{Cl}$ & Mean & $95 \% \mathrm{Cl}$ & & \\
\hline $\begin{array}{l}\text { Energy (MJ) } \\
\text { Fat total }\end{array}$ & 8.51 & $8 \cdot 18,8 \cdot 84$ & $8 \cdot 25$ & $7 \cdot 84,8 \cdot 66$ & $8 \cdot 41$ & $8 \cdot 07,8.75$ & $8 \cdot 27$ & $7 \cdot 84,8 \cdot 70$ & $8 \cdot 29$ & $7 \cdot 91,8 \cdot 66$ & 8.35 & $7 \cdot 97,8 \cdot 74$ & 0.661 & 0.932 \\
\hline $\mathrm{g}$ & $71 \cdot 1$ & $67 \cdot 4,74 \cdot 8$ & $71 \cdot 0$ & $66 \cdot 5,75 \cdot 5$ & $70 \cdot 1$ & $66 \cdot 1,74 \cdot 2$ & $71 \cdot 7$ & $67 \cdot 5,75 \cdot 8$ & $70 \cdot 0$ & $65 \cdot 7,74 \cdot 2$ & $73 \cdot 2$ & $69 \cdot 0,77 \cdot 5$ & 0.908 & 0.753 \\
\hline $\begin{array}{l}\text { E\% } \\
\text { SFA }\end{array}$ & $31 \cdot 3$ & $30 \cdot 5,32 \cdot 2$ & $32 \cdot 2$ & $31 \cdot 2,33 \cdot 3$ & $31 \cdot 2$ & $30 \cdot 2,32 \cdot 2$ & $32 \cdot 7$ & $31 \cdot 7,33 \cdot 6$ & $31 \cdot 6$ & $30 \cdot 6,32 \cdot 6$ & $33 \cdot 1$ & $31 \cdot 8,34 \cdot 4$ & 0.864 & 0.542 \\
\hline$\stackrel{\mathrm{g}}{\mathrm{E} \%}$ & $\begin{array}{l}27 \cdot 6 \\
12 \cdot 2\end{array}$ & $\begin{array}{l}25 \cdot 9,29 \cdot 3 \\
11 \cdot 7,12 \cdot 7\end{array}$ & $\begin{array}{l}26 \cdot 6 \\
12 \cdot 0\end{array}$ & $\begin{array}{l}24 \cdot 5,28 \cdot 6 \\
11 \cdot 4,12 \cdot 6\end{array}$ & $\begin{array}{l}27 \cdot 1 \\
12 \cdot 1\end{array}$ & $\begin{array}{l}25 \cdot 4,28 \cdot 8 \\
11 \cdot 6,12 \cdot 6\end{array}$ & $\begin{array}{l}26 \cdot 5 \\
12 \cdot 1\end{array}$ & $\begin{array}{l}24 \cdot 7,28 \cdot 4 \\
11 \cdot 5,12 \cdot 6\end{array}$ & $\begin{array}{l}29 \cdot 1 \\
13 \cdot 1\end{array}$ & $\begin{array}{l}27 \cdot 2,31 \cdot 0 \\
12 \cdot 6,13 \cdot 6\end{array}$ & $\begin{array}{l}30 \cdot 2 \\
13 \cdot 6\end{array}$ & $\begin{array}{l}28 \cdot 1,32 \cdot 2 \\
12 \cdot 9,14 \cdot 2\end{array}$ & $\begin{array}{l}0.277 \\
0.012\end{array}$ & $\begin{array}{r}0.014 \\
<0.001\end{array}$ \\
\hline MUFA & & & & & & & & & & & & & & \\
\hline$\stackrel{g}{\mathrm{E} \%}$ & $\begin{array}{l}24.9 \\
10 \cdot 9\end{array}$ & $\begin{array}{l}23 \cdot 4,26 \cdot 4 \\
10 \cdot 5,11 \cdot 4\end{array}$ & $\begin{array}{l}25 \cdot 2 \\
11 \cdot 4\end{array}$ & $\begin{array}{l}23 \cdot 5,26 \cdot 8 \\
11 \cdot 0,11 \cdot 9\end{array}$ & $\begin{array}{l}24 \cdot 4 \\
10 \cdot 8\end{array}$ & $\begin{array}{l}22 \cdot 8,26 \cdot 0 \\
10 \cdot 4,11 \cdot 3\end{array}$ & $\begin{array}{l}25 \cdot 5 \\
11.7\end{array}$ & $\begin{array}{l}24 \cdot 0,27 \cdot 0 \\
11 \cdot 2,12 \cdot 1\end{array}$ & $\begin{array}{l}23 \cdot 0 \\
10 \cdot 4\end{array}$ & $\begin{array}{l}21 \cdot 5,24 \cdot 5 \\
10 \cdot 0,10 \cdot 8\end{array}$ & $\begin{array}{l}23 \cdot 9 \\
10 \cdot 8\end{array}$ & $\begin{array}{l}22 \cdot 4,25 \cdot 3 \\
10 \cdot 3,11 \cdot 3\end{array}$ & $\begin{array}{l}0.188 \\
0.203\end{array}$ & $\begin{array}{l}0.296 \\
0.032\end{array}$ \\
\hline $\begin{array}{c}\text { PUFA } \\
\text { g } \\
\text { E\% }\end{array}$ & $\begin{array}{r}12.5 \\
5.5\end{array}$ & $\begin{array}{c}11 \cdot 8,13 \cdot 2 \\
5 \cdot 3,5 \cdot 8\end{array}$ & $\begin{array}{r}12 \cdot 8 \\
5 \cdot 8\end{array}$ & $\begin{array}{c}12 \cdot 0,13 \cdot 6 \\
5 \cdot 6,6 \cdot 1\end{array}$ & $\begin{array}{r}12.5 \\
5.5\end{array}$ & $\begin{array}{c}11 \cdot 6,13 \cdot 3 \\
5 \cdot 3,5 \cdot 8\end{array}$ & $\begin{array}{r}13 \cdot 5 \\
6 \cdot 2\end{array}$ & $\begin{array}{c}12 \cdot 6,14 \cdot 4 \\
5 \cdot 9,6 \cdot 5\end{array}$ & $\begin{array}{r}11.2 \\
5.1\end{array}$ & $\begin{array}{c}10 \cdot 4,12 \cdot 0 \\
4 \cdot 8,5 \cdot 3\end{array}$ & $\begin{array}{r}12 \cdot 0 \\
5.4\end{array}$ & $\begin{array}{c}11 \cdot 1,12 \cdot 8 \\
5 \cdot 1,5 \cdot 7\end{array}$ & $\begin{array}{l}0.029 \\
0.004\end{array}$ & $\begin{array}{l}0.045 \\
0.001\end{array}$ \\
\hline Protein & & & & & & & & & & & & & & \\
\hline$\stackrel{g}{\mathrm{E} \%}$ & $\begin{array}{l}81 \cdot 5 \\
16 \cdot 2\end{array}$ & $\begin{array}{l}77 \cdot 9,85 \cdot 1 \\
15 \cdot 7,16 \cdot 6\end{array}$ & $\begin{array}{l}83 \cdot 9 \\
17 \cdot 4\end{array}$ & $\begin{array}{l}79 \cdot 8,88 \cdot 0 \\
16 \cdot 7,18 \cdot 1\end{array}$ & $\begin{array}{l}82 \cdot 2 \\
16 \cdot 5\end{array}$ & $\begin{array}{l}78 \cdot 5,85 \cdot 8 \\
16 \cdot 1,17 \cdot 0\end{array}$ & $\begin{array}{l}82 \cdot 6 \\
16 \cdot 9\end{array}$ & $\begin{array}{l}77 \cdot 9,87 \cdot 3 \\
16 \cdot 3,17 \cdot 5\end{array}$ & $\begin{array}{l}81 \cdot 7 \\
16 \cdot 7\end{array}$ & $\begin{array}{l}77 \cdot 8,85 \cdot 6 \\
16 \cdot 3,17 \cdot 1\end{array}$ & $\begin{array}{l}84 \cdot 4 \\
17 \cdot 1\end{array}$ & $\begin{array}{l}80 \cdot 2,88 \cdot 7 \\
16 \cdot 6,17 \cdot 6\end{array}$ & $\begin{array}{l}0.965 \\
0.277\end{array}$ & $\begin{array}{l}0.833 \\
0.510\end{array}$ \\
\hline Carbohydrates & & & & & & & & & . & & & & & \\
\hline$\stackrel{\mathrm{g}}{\mathrm{E} \%}$ & $\begin{array}{r}257 \\
51.0\end{array}$ & $\begin{array}{c}247,268 \\
50 \cdot 1,51 \cdot 9\end{array}$ & $\begin{array}{r}240 \\
48 \cdot 6\end{array}$ & $\begin{array}{c}227,253 \\
47 \cdot 5,49 \cdot 8\end{array}$ & $\begin{array}{c}253 \\
50.8\end{array}$ & $\begin{array}{c}242,264 \\
49 \cdot 8,51 \cdot 9\end{array}$ & $\begin{array}{r}240 \\
48.6\end{array}$ & $\begin{array}{c}226,254 \\
47 \cdot 6,49 \cdot 6\end{array}$ & $\begin{array}{l}247 \\
50 \cdot 3\end{array}$ & $\begin{array}{c}236,258 \\
49 \cdot 2,51 \cdot 3\end{array}$ & $\begin{array}{l}240 \\
48 \cdot 1\end{array}$ & $\begin{array}{c}227,254 \\
46 \cdot 7,49 \cdot 4\end{array}$ & $\begin{array}{l}0.389 \\
0.579\end{array}$ & $\begin{array}{l}0.999 \\
0.761\end{array}$ \\
\hline Fibre (g) & 21.3 & $20 \cdot 0,22 \cdot 0$ & 19.5 & $18 \cdot 0,21 \cdot 0$ & 21.4 & $20 \cdot 1,22 \cdot 6$ & 21.0 & $19 \cdot 4,22 \cdot 7$ & 19.5 & $18 \cdot 3,20 \cdot 7$ & $18 \cdot 6$ & $17 \cdot 2,19 \cdot 9$ & 0.072 & 0.063 \\
\hline
\end{tabular}

E\%, percentage of energy.

at the first, second and third trimesters of pregnancy.

tThe mean of the intakes at 1 and 6 months postpartum. 
Table 3. Serum leptin concentrations $(\mathrm{ng} / \mathrm{ml})$ in women and their children

(Geometric mean values and $95 \%$ confidence intervals)

\begin{tabular}{|c|c|c|c|c|c|c|c|c|c|c|}
\hline & \multicolumn{3}{|c|}{ Dietary counselling with probiotics } & \multicolumn{3}{|c|}{ Dietary counselling with placebo } & \multicolumn{3}{|c|}{ Controls } & \multirow[b]{2}{*}{$P^{*}$} \\
\hline & Geometric mean & $95 \% \mathrm{Cl}$ & $n$ & Geometric mean & $95 \% \mathrm{Cl}$ & $n$ & Geometric mean & $95 \% \mathrm{Cl}$ & $n$ & \\
\hline \multicolumn{11}{|l|}{ Women } \\
\hline First trimester & $20 \cdot 0$ & $17 \cdot 5,22 \cdot 8$ & 84 & 23.7 & $20 \cdot 8,27 \cdot 0$ & 80 & $26 \cdot 0$ & $23 \cdot 0,29 \cdot 5$ & 78 & \\
\hline Third trimester & $26 \cdot 2$ & $23 \cdot 1,29 \cdot 7$ & 80 & $27 \cdot 5$ & $23.8,31 \cdot 8$ & 78 & 33.1 & $29 \cdot 2,37.4$ & 77 & 0.757 \\
\hline Postpartum & $12 \cdot 2$ & $9 \cdot 9,14.9$ & 78 & $14 \cdot 3$ & $11 \cdot 9,17 \cdot 2$ & 73 & $16 \cdot 7$ & $14 \cdot 3,19 \cdot 6$ & 73 & 0.793 \\
\hline \multirow{3}{*}{$\begin{array}{l}\text { Mean of the third } \\
\text { trimester and } \\
1 \text { month postpartum } \\
\text { (baseline adjusted) }\end{array}$} & $19 \cdot 9$ & $18 \cdot 1,22 \cdot 0$ & 78 & $20 \cdot 3$ & $18 \cdot 3,22 \cdot 6$ & 73 & $21 \cdot 1$ & $18 \cdot 9,23 \cdot 5$ & 73 & 0.760 \\
\hline & \multicolumn{3}{|c|}{ Dietary counselling with probiotics } & \multicolumn{3}{|c|}{ Dietary counselling with placebo } & \multicolumn{3}{|c|}{ Control with placebo } & \\
\hline & Geometric mean & $95 \% \mathrm{Cl}$ & $n$ & Geometric mean & $95 \% \mathrm{Cl}$ & $n$ & Geometric mean & $95 \% \mathrm{Cl}$ & $n$ & $P \dagger$ \\
\hline \multicolumn{11}{|l|}{ Children } \\
\hline Cord blood & $10 \cdot 5$ & $8 \cdot 5,13 \cdot 0$ & 60 & $10 \cdot 2$ & $8 \cdot 1,12 \cdot 8$ & 55 & $13 \cdot 0$ & $10 \cdot 5,16 \cdot 1$ & 48 & 0.236 \\
\hline 1 month of age & 3.9 & $3 \cdot 2,4 \cdot 8$ & 68 & $2 \cdot 9$ & $2 \cdot 4,3 \cdot 5$ & 40 & 3.7 & $2 \cdot 9,4 \cdot 6$ & 40 & 0.098 \\
\hline 6 months of age & 3.5 & $3 \cdot 0,4 \cdot 2$ & 64 & 3.4 & $3 \cdot 0,4 \cdot 0$ & 69 & 3.6 & $3 \cdot 0,4 \cdot 2$ & 63 & 0.938 \\
\hline $\begin{array}{l}\text { Mean of } 1 \text { and } \\
6 \text { months }\end{array}$ & $3 \cdot 9$ & $3.4,4.5$ & 55 & $3 \cdot 1$ & $2 \cdot 6,3 \cdot 7$ & 36 & 3.5 & $2 \cdot 9,4 \cdot 2$ & 33 & 0.328 \\
\hline
\end{tabular}

* Group comparisons were performed using ANCOVA for repeated measures, where the baseline (first-trimester) concentration was included as a covariate. The results are given as baseline-adjusted marginal means with $95 \% \mathrm{Cl}$.

† Group comparisons were performed using ANOVA.

were significantly decreased from the cord blood levels. Explanatory factors for cord blood leptin concentrations seemed to be the birth weight and sex of the infant as well as maternal leptin concentration and protein intake during pregnancy. During infancy, only birth weight and sex remain significant explanatory factors for leptin concentration.

We showed here that the elevation in leptin concentrations during pregnancy is in good agreement with earlier studies ${ }^{(24)}$. The moderate rise in leptin concentration most probably represents a normal pregnancy-related phenomenon leading to leptin resistance, which, in turn, ensures the adequate energy intake for both mother and child ${ }^{(25)}$. Nevertheless, it was previously evidenced that overweight women face highly elevated leptin concentrations with the progress of pregnancy; this is predisposing to aberrations in normal pregnancy-related adaptations in maternal metabolism ${ }^{(9)}$ and further to pre-eclampsia and gestational diabetes ${ }^{(26)}$. Indeed, here we showed that maternal pre-pregnancy overweight and excessive weight gain during pregnancy are the key determinants for highly elevated leptin concentrations during pregnancy. Therefore, it may be suggested that weight control both before and during pregnancy, in particular, avoidance of excessive weight gain during pregnancy, would provide the most effective approach to controlling the pregnancy-related increase in leptin concentration overemphasised in overweight individuals.

The novel findings here suggest that a higher dietary fibre intake and a lower intake of SFA may help to restrict the increase in leptin concentrations during pregnancy. In line with the present results, the amount of dietary fibre has been shown to be inversely associated with plasma leptin concentration in Japanese non-pregnant adults ${ }^{(27)}$. Clinical significance of fibre, in turn, has been evidenced both with healthy individuals and with metabolic syndrome patients who achieved significant improvements in metabolic syndrome risk factors with a high-fibre diet ${ }^{(14,28)}$. Moreover, a high-fibre diet has been suggested to attenuate pregnancy-associated dyslipidaemia and reduce the risk of pre-eclampsia and gestational hyperglycaemia ${ }^{(29,30)}$. Besides the beneficial effect of dietary fibre, the present study also suggests a

Table 4. Multivariate regression models explaining the women's (mean of the third trimester and 1 month postpartum) serum leptin concentrations

(Regression coefficients and $95 \%$ confidence intervals)

\begin{tabular}{lccr}
\hline Explanatory factors & Regression coefficient $(\beta)$ & $95 \% \mathrm{Cl}$ & \multicolumn{1}{c}{$P$} \\
\hline Dietary counselling & -0.115 & $-0.246,0.015$ & 0.084 \\
Probiotic supplementation & 0.057 & $-0.070,0.185$ & 0.376 \\
Baseline leptin concentration & 0.36 & $0.312,0.561$ & $<0.001$ \\
Pre-pregnancy BMI $\left(\mathrm{kg} / \mathrm{m}^{2}\right)$ & 0.052 & $0.033,0.072$ & $<0.001$ \\
Weight gain during pregnancy & 0.032 & $0.021,0.043$ & $<0.001$ \\
Fibre intake & -0.013 & $-0.021,-0.004$ & 0.003 \\
SFA intake & 0.006 & $0.000,0.012$ & 0.053 \\
\hline
\end{tabular}


Table 5. Multivariate forward stepwise regression model explaining cord blood leptin concentrations (Regression coefficients and $95 \%$ confidence intervals)

\begin{tabular}{|c|c|c|c|c|}
\hline Steps & Independent variables & Regression coefficient $(\beta)$ & $95 \% \mathrm{Cl}$ & $P$ \\
\hline \multirow[t]{2}{*}{1} & Dietary counselling & -0.195 & $-0.528,0.138$ & 0.248 \\
\hline & Probiotic supplementation & 0.051 & $-0.253,0.354$ & 0.742 \\
\hline \multirow[t]{3}{*}{2} & Dietary counselling & -0.114 & $0.410,0.182$ & 0.447 \\
\hline & Probiotic supplementation & 0.102 & $-0.167,0.371$ & 0.455 \\
\hline & Birth weight of the infant & 0.001 & $0.001,0.001$ & $<0.001$ \\
\hline \multirow[t]{4}{*}{3} & Dietary counselling & -0.125 & $-0.398,0.148$ & 0.366 \\
\hline & Probiotic supplementation & 0.114 & $-0.134,0.362$ & 0.366 \\
\hline & Birth weight of the infant & 0.001 & $0.001,0.001$ & $<0.001$ \\
\hline & Male sex & -0.556 & $-0.768,-0.344$ & $<0.001$ \\
\hline \multirow[t]{5}{*}{4} & Dietary counselling & -0.087 & $-0.354,0.180$ & 0.519 \\
\hline & Probiotic supplementation & 0.168 & $-0.076,0.413$ & 0.175 \\
\hline & Birth weight of the infant & 0.001 & $0.001,0.001$ & $<0.001$ \\
\hline & Male sex & -0.540 & $-0.747,-0.333$ & $<0.001$ \\
\hline & Maternal leptin concentration* & 0.313 & $0.110,0.516$ & 0.003 \\
\hline \multirow[t]{6}{*}{5} & Dietary counselling & -0.076 & $-0.340,0.187$ & 0.568 \\
\hline & Probiotic supplementation & 0.167 & $-0.074,0.408$ & 0.172 \\
\hline & Birth weight of the infant & 0.001 & $0.001,0.001$ & $<0.001$ \\
\hline & Male sex & -0.523 & $-0.727,-0.318$ & $<0.001$ \\
\hline & Maternal leptin concentration* & 0.276 & $0.073,0.478$ & 0.008 \\
\hline & Maternal protein intake $\dagger$ & -0.007 & $-0.013,-0.001$ & 0.024 \\
\hline
\end{tabular}

potential detrimental impact of SFA in increasing leptin concentrations. In line with the present results and current dietary recommendations ${ }^{(31)}$, recent epidemiological studies and randomised trials have suggested that replacing saturated fat with polyunsaturated fat decreases the risk of $\mathrm{CHD}^{(32)}$. Furthermore, during pregnancy, a lower dietary intake of SFA has been proposed for decreasing the risk of gestational hyperglycaemia $^{(33)}$. Altogether, these findings suggest that a diet rich in fibre and low in saturated fat may provide both short- and long-term health benefits to both women and their children by controlling the pregnancy-related increase in leptin concentration.

Similar to earlier studies ${ }^{(34,35)}$, the present results suggest here that both cord blood serum and infant serum leptin concentrations are positively associated with infants' birth weight and female sex. The difference in leptin concentrations between the sexes may result from a varying amount and distribution of body fat in infants ${ }^{(34)}$. On the other hand, sex-specific adaptations taking place during the fetal period in the placenta may explain the difference in leptin concentrations. Indeed, these adaptations have been suggested, in turn leading to differences in growth and metabolic and immune functions between female and male infants ${ }^{(36)}$. Interestingly, higher maternal dietary protein intake during pregnancy seemed to decrease cord blood leptin concentration. Nevertheless, the clinical significance of this finding remains to be shown.

Breast milk leptin concentrations were not measured in the present study. We acknowledge that it is a weakness of the study since others have suggested that breast milk leptin could provide a link between maternal body composition and infant growth ${ }^{(37,38)}$. Here we found a positive relationship between infant weight and leptin concentration in all the studied time points and, additionally, a weak negative correlation between cord blood leptin concentration and infant weight at 6 months of age. This is in line with earlier studies suggesting that lower cord blood leptin levels are associated with pronounced weight gain $^{(39)}$ and that higher neonatal leptin predicts slower weight gain $^{(40)}$ in the first 6 months of life. Nevertheless, no conclusions about the relationships between

Table 6. Multivariate regression models explaining children's (mean of 1 and 6 months of age) serum leptin concentrations

(Regression coefficients and $95 \%$ confidence intervals)

\begin{tabular}{lccc}
\hline Explanatory factors & Regression coefficient $(\beta)$ & $95 \% \mathrm{Cl}$ & $P$ \\
\hline Dietary counselling & -0.132 & $-0.340,0.075$ & 0.210 \\
Probiotic supplementation & 0.176 & $-0.027,0.379$ & 0.090 \\
Male sex & -0.221 & $-0.388,-0.054$ & 0.010 \\
Birth weight of the infant $_{\text {Maternal energy intake }}^{*}$ & 0.193 & $0.004,0.382$ & 0.045 \\
Maternal carbohydrate intake* $^{*}$ & -0.007 & $-0.123,0.110$ & 0.912 \\
Maternal fibre intake $^{*}$ & -0.001 & $-0.004,0.003$ & 0.713 \\
\hline
\end{tabular}

* Maternal intake of energy, carbohydrates and fibre as a mean of the third trimester and 1 month postpartum. 
early-life leptin levels and later obesity risk can be drawn based on the present results, but still the present study with a unique study population comprises an encouraging starting point for future analysis.

In summary, we conclude that particularly in overweight women, weight control both before and during pregnancy as well as the modification of diet towards higher fibre and lower SFA intakes may provide an effective approach to controlling the pregnancy-related increase in leptin concentration in women. This may consequently lead to more balanced maternal metabolism during pregnancy and provide later health benefits for both women and their children.

\section{Acknowledgements}

We would like to thank Ms Ulla-Maija Eriksson for the clinical work she conducted with the study subjects and Ms Satu Leinonen for the technical work. The present study was supported by grants from the Social Insurance Institution of Finland, the Sigrid Juselius Foundation, the Jenny and Antti Wihuri Foundation (personal S. V.) and the Juho Vainio Foundation (personal S. V.). The food products were provided by Raisio plc (Raisio). The authors' responsibilities were as follows: K. L. and E. I. contributed to the study concept and design; S. V. and K. L. carried out the collection of the data. All authors participated in the preparation of the manuscript. None of the authors had a conflict of interest to declare.

\section{References}

1. Dardeno TA, Chou SH, Moon HS, et al. (2010) Leptin in human physiology and therapeutics. Front Neuroendocrinol 31, 377-393.

2. Myers MG Jr, Leibel RL, Seeley RJ, et al. (2010) Obesity and leptin resistance: distinguishing cause from effect. Trends Endocrinol Metab 21, 643-651.

3. Deng Y \& Scherer PE (2010) Adipokines as novel biomarkers and regulators of the metabolic syndrome. Ann N Y Acad Sci 1212, E1-E19.

4. Karlsson EA \& Beck MA (2010) The burden of obesity on infectious disease. Exp Biol Med (Maywood) 235 , 1412-1424.

5. Kajikawa Y, Ikeda M, Takemoto S, et al. (2011) Association of circulating levels of leptin and adiponectin with metabolic syndrome and coronary heart disease in patients with various coronary risk factors. Int Heart J 52, 17-22.

6. Mai XM, Chen Y \& Krewski D (2009) Does leptin play a role in obesity-asthma relationship? Pediatr Allergy Immunol 20, 207-212.

7. Ciprandi G, De Amici M, Tosca MA, et al. (2009) Serum leptin levels depend on allergen exposure in patients with seasonal allergic rhinitis. Immunol Invest 38, 681-689.

8. Quek YW, Sun HL, Ng YY, et al. (2010) Associations of serum leptin with atopic asthma and allergic rhinitis in children. Am J Rhinol Allergy 24, 354-358.

9. Vahamiko S, Isolauri E, Pesonen U, et al. (2010) Dietary sucrose intake is related to serum leptin concentration in overweight pregnant women. Eur J Nutr 49, 83-90.

10. Heerwagen MJ, Miller MR, Barbour LA, et al. (2010) Maternal obesity and fetal metabolic programming: a fertile epigenetic soil. Am J Physiol Regul Integr Comp Physiol 299, $\mathrm{R} 711-\mathrm{R} 722$.
11. Butte NF, Hopkinson JM, Mehta N, et al. (1999) Adjustments in energy expenditure and substrate utilization during late pregnancy and lactation. Am J Clin Nutr 69, 299-307.

12. Fraser A, Tilling K, Macdonald-Wallis C, et al. (2010) Association of maternal weight gain in pregnancy with offspring obesity and metabolic and vascular traits in childhood. Circulation 121, 2557-2564.

13. Djiane J \& Attig L (2008) Role of leptin during perinatal metabolic programming and obesity. J Physiol Pharmacol 59, Suppl. 1, 55-63.

14. Tighe P, Duthie G, Vaughan N, et al. (2010) Effect of increased consumption of whole-grain foods on blood pressure and other cardiovascular risk markers in healthy middle-aged persons: a randomized controlled trial. $\mathrm{Am} \mathrm{J}$ Clin Nutr 92, 733-740.

15. Micallef MA, Munro IA \& Garg ML (2009) An inverse relationship between plasma $n$ - 3 fatty acids and C-reactive protein in healthy individuals. Eur J Clin Nutr 63, 1154-1156.

16. Malik VS, Popkin BM, Bray GA, et al. (2010) Sugar-sweetened beverages, obesity, type 2 diabetes mellitus, and cardiovascular disease risk. Circulation 121, 1356-1364.

17. Laitinen K, Poussa T \& Isolauri E (2009) Probiotics and dietary counselling contribute to glucose regulation during and after pregnancy: a randomised controlled trial. $\mathrm{Br} J \mathrm{Nutr}$ 101, 1679-1687.

18. Musso G, Gambino R \& Cassader M (2010) Gut microbiota as a regulator of energy homeostasis and ectopic fat deposition: mechanisms and implications for metabolic disorders. Curr Opin Lipidol 21, 76-83.

19. Chapman CM, Gibson GR \& Rowland I (2011) Health benefits of probiotics: are mixtures more effective than single strains? Eur J Nutr 50, 1-17.

20. Piirainen T, Isolauri E, Lagstrom $\mathrm{H}$, et al. (2006) Impact of dietary counselling on nutrient intake during pregnancy: a prospective cohort study. Br J Nutr 96, 1095-1104.

21. Aaltonen J, Ojala T, Laitinen K, et al. (2008) Evidence of infant blood pressure programming by maternal nutrition during pregnancy: a prospective randomized controlled intervention study. J Pediatr 152, 79-84, 84.e1-2.

22. Institute of Medicine (1990) Subcommittee on Nutritional Status and Weight Gain during Pregnancy. Nutrition During Pregnancy. Washington, DC: National Academy Press.

23. Huurre A, Laitinen K, Rautava S, et al. (2008) Impact of maternal atopy and probiotic supplementation during pregnancy on infant sensitization: a double-blind placebo-controlled study. Clin Exp Allergy 38, 1342-1348.

24. Henson MC \& Castracane VD (2006) Leptin in pregnancy: an update. Biol Reprod 74, 218-229.

25. Grattan DR, Ladyman SR \& Augustine RA (2007) Hormonal induction of leptin resistance during pregnancy. Physiol Behav 91, 366-374.

26. Briana DD \& Malamitsi-Puchner A (2009) Reviews: adipocytokines in normal and complicated pregnancies. Reprod Sci 16, 921-937.

27. Kuroda M, Ohta M, Okufuji T, et al. (2010) Frequency of soup intake and amount of dietary fiber intake are inversely associated with plasma leptin concentrations in Japanese adults. Appetite 54, 538-543.

28. Pal S, Khossousi A, Binns C, et al. (2011) The effect of a fibre supplement compared to a healthy diet on body composition, lipids, glucose, insulin and other metabolic syndrome risk factors in overweight and obese individuals. Br J Nutr 105, 90-100. 
29. Qiu C, Coughlin KB, Frederick IO, et al. (2008) Dietary fiber intake in early pregnancy and risk of subsequent preeclampsia. Am J Hypertens 21, 903-909.

30. Zhang C, Liu S, Solomon CG, et al. (2006) Dietary fiber intake, dietary glycemic load, and the risk for gestational diabetes mellitus. Diabetes Care 29, 2223-2230.

31. Becker W, Lyhne N, Pedersen AN, et al. (2004) Nordic Nutrition Recommendations 2004 - integrating nutrition and physical activity. Scand J Nutr 48, 178-187.

32. Siri-Tarino PW, Sun Q, Hu FB, et al. (2010) Saturated fat, carbohydrate, and cardiovascular disease. Am J Clin Nutr 91, 502-509.

33. Bo S, Menato G, Lezo A, et al. (2001) Dietary fat and gestational hyperglycaemia. Diabetologia 44, 972-978.

34. Trevino-Garza C, Bosques-Padilla FJ, Estrada-Zuniga CM, et al. (2010) Typical leptin fall is mitigated by breastfeeding in female infants. Arch Med Res 41, 373-377.

35. Mellati AA, Mazloomzadeh S, Anjomshoaa A, et al. (2010) Multiple correlations between cord blood leptin concen- tration and indices of neonatal growth. Arch Med Res $\mathbf{4 1}$ $26-32$.

36. Clifton VL (2010) Review: sex and the human placenta: mediating differential strategies of fetal growth and survival. Placenta 31, S33-S39.

37. Schuster S, Hechler C, Gebauer C, et al. (2011) Leptin in maternal serum and breast milk: association with infants' body weight gain in a longitudinal study over 6 months of lactation. Pediatr Res 70, 633-637.

38. Miralles O, Sanchez J, Palou A, et al. (2006) A physiological role of breast milk leptin in body weight control in developing infants. Obesity (Silver Spring) 14, 1371-1377.

39. Mantzoros CS, Rifas-Shiman SL, Williams CJ, et al. (2009) Cord blood leptin and adiponectin as predictors of adiposity in children at 3 years of age: a prospective cohort study. Pediatrics 123, 682-689.

40. Parker M, Rifas-Shiman SL, Belfort MB, et al. (2011) Gestational glucose tolerance and cord blood leptin levels predict slower weight gain in early infancy. J Pediatr 158, 227-233. 